\title{
Legal Dimensions of Adolescent Sexuality
}

Roxanne Mykitiuk

Osgoode Hall Law School of York University, rmykitiuk@osgoode.yorku.ca

Stephanie Turnham

Source Publication:

Journal of Obstetrics and Gynaecology Canada. Volume 26 (2004), p. 991-999.

Follow this and additional works at: https://digitalcommons.osgoode.yorku.ca/scholarly_works

Part of the Health Law and Policy Commons, Legal Ethics and Professional Responsibility Commons, and the Sexuality and the Law Commons

c) (1) $(9)$

This work is licensed under a Creative Commons Attribution-Noncommercial-No Derivative Works 4.0 License.

\section{Recommended Citation}

Mykitiuk, Roxanne, and Stephanie Turnham. "Legal Dimensions of Adolescent Sexuality." Journal of Obstetrics and Gynaecology Canada 26 (2004): 991-999.

This Article is brought to you for free and open access by the Faculty Scholarship at Osgoode Digital Commons. It has been accepted for inclusion in Articles \& Book Chapters by an authorized administrator of Osgoode Digital Commons. 


\title{
LegAl Dimensions of Adolescent Sexuality
}

\author{
Roxanne Mykitiuk, LLB, LLM, Stephanie Turnham, BA (Hons), LLB Candidate \\ Osgoode Hall Law School, York University, Toronto ON
}

\begin{abstract}
The ethical and legal obligations with respect to treating a minor can be confusing, particularly in the areas of consent to treatment, confidentiality, and parental involvement. The clinician must be aware of the appropriate course of practice when the patient is an adolescent seeking care for contraception, pregnancy, or sexually transmitted infections. This article examines a number of ethical and legal issues that arise when providing reproductive and sexual health care to an adolescent and offers recommendations for the physician's most appropriate courses of action regarding adolescent patients and the age of consent to sexual activity, reporting of child abuse, provision of reproductive and sexual health care to a minor, assessing an adolescent's capacity to consent to treatment, the physician's duty of confidentiality, and the exceptions to the rule of confidentiality.
\end{abstract}

\section{Résumé}

Les obligations éthiques et juridiques associées au traitement d'une personne mineure peuvent être déroutantes, particulièrement dans les domaines du consentement au traitement, de la confidentialité et de la participation parentale. Le clinicien doit être au fait des modalités de pratique appropriées face à une patiente adolescente sollicitant ses services en matière de contraception, de grossesse ou d'infections transmissibles sexuellement. Le présent article se penche sur un certain nombre de questions éthiques et juridiques liées à l'offre de soins de santé sexuelle et génésique à une adolescente, et offre des recommandations aux médecins quant aux lignes de conduite les plus indiquées en ce qui concerne les patientes adolescentes et l'âge requis pour consentir à des relations sexuelles, le signalement des cas de violence faite aux enfants, l'offre de soins de santé sexuelle et génésique à une personne mineure, l'évaluation de la capacité d'une adolescente à consentir au traitement, l'obligation de confidentialité du médecin et les exceptions à la règle de la confidentialité.

J Obstet Gynaecol Can 2004;26(II):991-9.

\section{Key Words}

Adolescent health services, confidentiality, parental consent, parental notification, contraception

Competing interests: None declared.

Received on May 13, 2004

Revised and accepted on September 16, 2004

\section{INTRODUCTION}

Physicians who provide care for adolescents are often concerned regarding their ethical and legal obligations, particularly in the areas of consent to treatment and parental involvement. Indeed, these obligations are often misunderstood. ${ }^{1,2}$ These concerns are compounded when the medical care involves reproductive and sexual health, services not uncommonly sought by adolescents. Adolescence is characterized as a time of increased sexual awareness and curiosity, during which adolescents may, and often do, become sexually active. In turn, they may seek medical advice or treatment for contraception, sexually transmitted infections (STIs), or pregnancy. ${ }^{3}$

However, it is also well-known that adolescents may be reluctant to confide in their parents. Not only are adolescents seeking to assert their own independence and autonomy, but sexuality can be a difficult and embarrassing subject to discuss. At the same time, parents are often unwilling to relinquish control over their child's well-being and may resist their child's claims to independence. Within this framework of competing interests, the medical practitioner is often at a loss as to how to proceed. Is it always acceptable to prescribe contraceptives without parental consent? How should one deal with parents who ask direct questions about their child's health? Is an adolescent capable of consenting to abortion? What is the appropriate course of action if the physician suspects child abuse, venereal disease, or a non-consensual sexual relationship?

The objectives of this article are 2-fold: to explore and expand upon the ethical and legal questions raised when providing reproductive and sexual health services to adolescents; and to offer physicians recommendations for the most appropriate courses of action when providing these services to adolescents. The discussion will focus on ethical and legal considerations, supplemented by policy and pragmatic concerns.

\section{AGE OF CONSENT TO SEXUAL ACTIVITY}

Physicians will benefit from a solid understanding of the laws regarding legal age of consent to sexual activity. First, physicians will be better equipped to answer a young patient's questions regarding legal age of consent. Second, physicians have an ethical duty to ensure that an adolescent patient is involved in a consensual sexual relationship that is free of coercion and abuse, ${ }^{4}$ 
and the law addressing the legal age of consent to sexual activity can provide useful guidelines.

Under the Criminal Code, there are 2 sets of sexual offences: those that apply equally to all persons, and those that apply only to child victims. The former category describes the 3 levels of sexual assault, ${ }^{5}$ defined as any case of non-consensual sexual touching, ${ }^{6}$ (p. 23) or any "assault with sexual overtones." 7 (p. 537) Sexual assault can also occur when the aggressor is not seeking sexual gratification. 8,9

Regarding the latter, while the Criminal Code contains no definition of "child," it effectively sets the age of consent to sexual activity at age $14 .^{10,11}$ A child under age 14 is incapable of consenting to sex, and it is irrelevant whether the child initiated the act. ${ }^{12}$ The only exception to this rule occurs when the parties are within 2 years of each other's age and there is no relation of trust or dependency. ${ }^{13}$ For example, a 15 -year-old who engages in consensual sex with a 13-year-old can rely on the defence of consent. Clearly, this exception exists to allow for sexual experimentation among youths. However, the law draws the line at age 12 . At no time is sexual activity with a person younger than 12 years of age acceptable.

While 14 years of age is the presumed minimum age of consent, the law also recognizes the particular vulnerability of adolescents in their relationships with parents, teachers, counsellors, coaches, and other authority figures. Accordingly, it is an offence for persons in positions of trust or authority to engage in sexual activity with someone younger than age 18 , or when a relationship of dependency exists. ${ }^{14}$ As long as there is no relationship of trust or dependency, youths aged 14 are presumed legally competent to consent to sex, in spite of recent reform movements that have called for raising the age of consent to $16 .{ }^{15,16}$

When an adolescent approaches a physician for reproductive or sexual health care, it is important for the physician to clarify how the adolescent defines sexual activity. Some adolescents might take the attitude that intimate relations falling short of intercourse, such as oral sex, do not count as sexual activity. ${ }^{17}$ They may therefore give misleading answers when asked if they are sexually active. The Criminal Code definition of sexual activity is broadly worded as touching, "for a sexual purpose ... directly or indirectly ... any part of the body." ${ }^{10}$ The Supreme Court of Canada has clarified that whether or not an activity is sexual depends on an objective assessment of all the circumstances, including the part of the body touched, the nature of the contact, the situation, any words or gestures, and the intent or purpose. ${ }^{18}$ It is clear that the definition of sexual activity, for the purposes of the Criminal Code, is not limited to intercourse. Also, while anal intercourse was treated as a separate category in the past, today it is treated no differently from any other sexual activity. ${ }^{19-21}$ Physicians need to be aware of the law's expansive definition of sex, in order to advise their patients that sexual activity is not limited to intercourse.

\section{LABILITY FOR PROVIDING MEDICAL ADVICE OR TREATMENT}

What do these legal definitions mean for a health-care provider? What are the responsibilities of a physician who knows that a patient is engaging in sexual relations with someone younger than age 14? Can a physician be implicated in the criminal offence? First, it is important to note that these laws do not make offenders of the under-aged adolescents who are not in a position of authority, but only of the older sexual partner. Physicians who provide under-aged adolescents with protection against pregnancy and STIs are not parties to any offence. The law recognizes that the physician's intention is not to promote unlawful sex, but to act in the best interest of the adolescent by providing protection against the unwanted consequences of sex. ${ }^{22}$ However, the situation is more sensitive when the patient is the older sexual partner. As it is illegal to counsel and equip a person to commit a criminal offence, physicians should ensure that their actions and advice do not amount to an endorsement of sexual relations with a specific under-aged partner. General advice on STIs or pregnancy would still be appropriate. ${ }^{23} \mathrm{~A}$ physician who receives information about an offence or possible offence is under no obligation to inform or assist the police, ${ }^{24}$ unless the perpetrator appears to be "dangerous," in terms of causing child abuse or transmitting STIs. The best course of action is to respect confidentiality and "leave the police work to the police." ${ }^{25,26}$ According to Justice Horace Krever: "A free exchange of information between physicians and hospitals and police should not be encouraged or permitted. Certainly physicians, hospital employees and other health-care workers ought not to be made part of the law enforcement machinery of the state."27 (p. 91)

A question that has yet to be addressed in Canada is whether a physician would be liable to a patient for volunteering information to the police about a potential or actual sexual crime. Scholars tend to agree that no legal liability would attach to the physician, but professional disciplinary committees may find that the potential "public good" in this case does not warrant overriding the ethical duty of confidentiality (discussed below). ${ }^{24}$

\section{REPORTING CHILD ABUSE}

In Canada, each province has child protection legislation ${ }^{28-34}$ requiring that all cases of suspected child abuse, including sexual abuse, be investigated to determine if a child is "in need of protection." 35 Although the legislation varies, a child is generally "in need of protection" when an act or omission of the parent or guardian threatens to cause harm to the child. Each statute imposes upon health-care professionals a mandatory duty to report suspected abuse immediately to the appropriate authority, a duty that explicitly overrides any applicable confidentiality rules. The laws expressly protect informers from 
liability, unless the informer acts maliciously or without reasonable grounds for the suspicion.

In light of these provisions, there is a question about whether a physician is obligated to report an under-aged sexual relationship as a suspicion of child abuse. First, it is important to keep in mind that the bar for reporting is set very low. In other words, a physician would never be reprimanded for reporting a reasonable suspicion; on the contrary, a physician may be reprimanded if there had been suspicion that the sexual relationship had an underlying abusive element, and it was not reported (personal communication with Ruth Warner, College of Physicians and Surgeons of Ontario, June 30, 2004). Moreover, it is not the physician's role or responsibility to investigate or confirm the abuse. Rather, the physician has a duty to report the suspicion, and the child protection authorities have the responsibility to conduct the investigation.

What, then, constitutes a reasonable suspicion of abuse? There is some ambiguity about whether the definition of harm is broad enough to encompass every case of under-aged sexual activity. Most provinces do not include an express definition of sexual abuse in the legislation. Alberta's statute provides the following definition: "a child is sexually abused if the child is inappropriately exposed or subjected to sexual contact, activity or behaviour." $30[\mathrm{s.} 3(3)(\mathrm{c})]$ Saskatchewan's statute makes reference to "harmful interaction for a sexual purpose ... including conduct that may amount to an offence within the meaning of the Criminal Code." 31 [s. 11(a)(iii)] British Columbia's Ministry of Children and Family Development also cites the Criminal Code offences, and states that "sexual abuse is any behaviour of a sexual nature toward a child." But this excludes "consensual, developmentally appropriate sexual activity between children where there is no significant difference in age or power between the children." 36

An authority from the Ontario Association of Children's Aid Societies suggests that any sexual relationship with a child may raise at least a suspicion of abuse. In Ontario, the duty to report is most obvious when the older person is an adult, or when the older person can be deemed to have "charge" of the child. There would also be a concern if the parents have reason to know about the relationship, because this may be considered a case of delegated control or lack of supervision. Because the parents need only have "constructive" knowledge, not actual knowledge, physicians should ask themselves what the reasonable parent in similar circumstances would know or should know about the child's sexual relationship. If the parent has a suspicion but chooses to ignore it, such suspicion counts as knowledge (personal communication with Marvin Bernstein, Director of Policy Development and Legal Support, Ontario Association of Children's Aid Societies, July 28, 2004). Similarly, if the child was not appropriately supervised - for example, if the parents went away for a vacation and left the child on his or her own-this situation would be cause for concern (per- sonal communication with Dianne Ternan, Children's Aid Society of Toronto, June 30, 2004). However, it is acknowledged that there is a grey area when the older person is not in charge or when there is uncertainty about the state of the parents' knowledge; and in such cases, it may be incumbent upon the physician to ask more questions. However, physicians need not conduct "mini-investigations" nor continue asking questions in the hope of finding a reason not to report the suspicion. The duty to report always overrides the duty of confidentiality, to be discussed below (personal communication with Marvin Bernstein, Director of Policy Development and Legal Support, Ontario Association of Children's Aid Societies, July 28, 2004).

These reporting requirements are clearly directed towards ensuring child safety, but compelling arguments have been raised against a mandatory duty to report under-aged sex. In the interests of ensuring that minors have access to confidential sexual health services, there may be situations in which reporting an under-aged relationship would cause more harm to the child than not reporting it. In disclosing information to a child protection agency, one takes the risk that the agency will contact the child's parents. This is a concern because many sexually active adolescents will not seek out these medical services if confidentiality cannot be ensured. ${ }^{1,3,37,38}$ A U.S. federal judge recently appeared to support the argument that mandatory reporting of under-aged sex would discourage minors from seeking medical services, by allowing a preliminary injunction against such reports in a specific case under Kansas law. ${ }^{39}$ The outcome of this case remains to be seen.

One way to exercise professional judgment with respect to abuse is to pay attention to what the child says about the relationship. For example, a physician might ask, "Are you feeling pressured?" and "Do you really feel ready for this kind of relationship?" (personal communication with Ruth Warner, College of Physicians and Surgeons of Ontario, June 30, 2004). The answers may provide an indication of whether the child is at immediate risk of harm. If there is no immediate risk to the child, the physician may need to make a judgment call. In any event, when the physician feels compelled to make a report, this decision should never be kept secret from the patient. Physicians should always try to make the call with the child in the room. The physician can even suggest that the child make the call. This strategy can be a way to maintain trust in the physician-patient relationship to the fullest possible extent. But note that the obligation to report any suspicious activity remains in force even when the child refuses to consent to the call (personal communication with Ruth Warner, College of Physicians and Surgeons of Ontario, June 30, 2004).

\section{PROVIDING REPRODUCTIVE AND SEXUAL HEALTH CARE TO A MINOR}

When an adolescent requests sexual health care, including 
contraceptive treatment, abortion, or SII management, the physician should consider 3 questions. First, does this patient have the capacity to consent to this treatment? Second, should the parents be contacted? Finally, what type of information should be provided to this patient, and to what extent? This section will clarify the issues of capacity and informed consent, and will offer some ethical, legal, and practical guidelines for prescribing contraceptives to minors.

\section{CONSENT TO TREATMENT}

\section{BACKGROUND}

Ethical and legal doctrines no longer follow the paternalistic model of medicine, in which the physician had a monopoly of power or knowledge over the patient. The physician-patient relationship "is becoming more egalitarian and participatory," while the "'doctor knows best' attitude has become increasingly unacceptable." 24 (p. 21-2) The laws of consent are designed to ensure that the patient is actively involved in the decisionmaking process.

Under the common law, the physician must ensure 2 conditions have been met. Step 1 addresses capacity to consent for treatment. To avoid liability for battery, ${ }^{40}$ (p. 9) the patient must have the capacity to consent to treatment. Step 2 addresses dis-

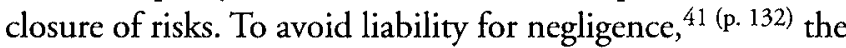
patient must receive a proper disclosure of information.

\section{STEP 1: The "Mature Minor"}

Capacity to consent to treatment should not be confused with either the age of majority or the age of consent to sexual activity. Capacity is a legal construct, ${ }^{42}$ based on a person's ability to understand the nature and consequences of the proposed treatment. The law recognizes that there is no logical connection between decisional capacity and age in the context of medical treatment. Therefore, capacity is assessed using a flexible caseby-case approach. In the absence of legislation to the contrary, a minor who has the necessary cognitive capacity to understand and make decisions about treatment is deemed a "mature minor," and is capable of consenting to treatment, without parental consent. Parents have no veto power over a mature minor's decision. ${ }^{41,43}$

At the same time, some provinces have enacted legislation that codifies and/or clarifies the law regarding a minor's capacity to consent to treatment. For example, Ontario's legislation ${ }^{44}$ creates a presumption of capacity for all persons, on which a physician may rely unless there is reasonable evidence to the contrary. Capacity is defined as the ability to understand the information relevant to making a treatment decision, and to appreciate the reasonably foreseeable consequences of a decision or lack of decision. ${ }^{45}$ In contrast, British Columbia has no clear presumption of capacity; rather, the onus is placed on the physician to make a determination of capacity. ${ }^{46}$ Capacity is defined as the ability to understand the nature and consequences of the treatment and the reasonably foreseeable risks and benefits. However, consent is only valid if the physician also determines that the treatment is in the child's "best interests." New Brunswick's legislation has a similar requirement, but sets a presumption of capacity at age $16 .{ }^{47}$ Manitoba also makes this presumption, but adds a presumption of incapacity below age 16. ${ }^{48}$ The common law, as described above, governs in those provinces without legislation.

These variations in the definitions of capacity and consent place physicians in a precarious situation. ${ }^{3}$ In the absence of any statutory presumptions, the responsibility rests with physicians to make the determination of capacity, ${ }^{49}$ and treating a person who has been determined to be "incapable" creates a risk of liability. From the outset, it is important to keep in mind that capacity can vary both across patients and across treatments. It is quite possible for a child to be able to consent to one treatment but not another because of the ability to understand one treatment but not the other. Similarly, two children of the same age may have different capacities to consent to the same treatment. ${ }^{41}$

Whether or not a child has the ability to understand the nature of the decision and to make a voluntary choice is influenced by emotional, psychological, and social maturity. ${ }^{42}$ These factors were recognized in 1995 by the Manitoba Law Reform Commission:

maturity may involve more than an intellectual appreciation of the nature and risks of the medical treatment per se. The court may also consider ethical, emotional maturity, particularly in difficult and controversial areas such as contraceptive treatment, abortion and the treatment of sexually transmitted disease. ${ }^{50}$

Desire to conform may be an important influence on an adolescent's decision-making, with the greatest tendency toward conformity occurring in early adolescence, with deference to requests for consent being most prevalent between the ages of 15 and $17 .{ }^{3}$ If an adolescent is merely consenting to the treatment out of deference, the physician should question whether the adolescent truly understands the nature of the procedure. Maturity and understanding also do not progress in a constant or uniform pattern, and will develop at different rates for different individuals. "Maturity in an adolescent can be a moving target." 42 (p. 211)

At this point, it is important to distinguish between American and Canadian legal principles, because they are sometimes confused. Under American law, an "emancipated minor"namely, a minor who is married or is living independently from parents-is deemed an adult for the purposes of consent to treatment. ${ }^{41}$ In Canada, some health facilities and professionals 
rely on this principle to a degree greater than is warranted. Compared to their parents' generation, youths today tend to remain living with their parents longer and enter the workforce later. At the same time, they are more independent in other respects, such as sexual activity. ${ }^{42}$ Thus, when determining the capacity to consent, the focus in Canada has shifted to intellectual and emotional maturity. The correct approach should be to take evidence of emancipation from parental control as merely an indicator of maturity, rather than the final determinant.

Physicians can only use their best judgment when assessing an adolescent's capacity. When the adolescent's family has been attending the same physician for some time, it will be easier to make an assessment than when the adolescent is meeting the physician for the first time. In the latter cases, the physician should endeavour to have as lengthy a conversation as possible, in order to inquire into the adolescent's relationship with the parents and the possibility of parental involvement. It would also be helpful in all cases to ask directed questions regarding the adolescent's understanding of the health issue, the therapeutic strategy, and the consequences of consenting or not consenting. Some examples that have been identified include: "What can you tell me about the nature of this treatment?"; "Do you think you need this treatment?"; "How might this treatment help you?"; and "What are any possible risks for you in consenting to this treatment?" 51 (p. 68) At all times, it would be prudent to make detailed notes of the assessment for future reference.

\section{“Best INTERests" OF THE CHILD}

As noted above, provincial legislation differs in the extent to which the physician's role is defined. British Columbia and New Brunswick have adopted the requirement that the treatment be in "the best interests" of the child, sometimes known as the "welfare principle." 12 Unfortunately, the law is unclear on the meaning of "best interests," and it remains unclear whether such a requirement is necessary even when the term is not explicitly addressed in legislation. For example, the Supreme Court of Canada has explained that the child's best interests are to be determined "from the standpoint of the child and not from the standpoint of the parents." 52 (p. 1080) However, the British Columbia Superior Court has held that moral and family issues may be relevant factors, and that in some circumstances, consultation with parents may be necessary in the best interests of the child. ${ }^{24,53}$

Since best interests are to be determined from the standpoint of the child, it has been suggested that abiding by a mature minor's decision is presumptively in the minor's best interests. ${ }^{42,54}$ The child's best interests should not be confused with medical opinion. Ultimately, the courts are comfortable to leave the determination of a child's best interests in the hands of the physician, "for they know that medical practitioners will be held accountable by their professional body if they fail to properly discharge this responsibility." 53 (para. 27) In those provinces where the child's best interests are addressed by legislation, the physician is obligated to consider the best interests of the patient when making decisions regarding treatment. However, in all other provinces, questions remain about the application of the welfare principle.

\section{CONSENT to CONTRACEPTION}

Turning now to sexual health care in particular, all clinicians should be aware that the law treats non-surgical contraceptives, such as intrauterine devices (IUDs), pharmaceuticals and condoms, no differently from any other medical device with respect to capacity to consent. ${ }^{41}$ However, the minor would have to be able to provide sufficient personal and medical family history regarding risk factors associated with taking oral contraceptives. ${ }^{55}$

\section{Consent to Surgical Procedure, Such as Abortion}

The principles of consent to treatment also apply to surgical procedures such as abortions, ${ }^{56}$ subject only to hospital management regulations. Indeed, it has been argued that any girl who asks for such a procedure is sufficiently competent to consent, given that a decision to undergo an abortion is not a choice to be taken lightly. ${ }^{37} \mathrm{~A}$ similar argument has also been made with respect to testing for STIs. ${ }^{1}$ Moreover, the public interest is best served by allowing an adolescent to obtain an abortion, rather than by forcing her to take on responsibilities for which she is not equipped.

As abortions are often performed in hospitals, it is important to be mindful of hospital regulations in each province. Consent to surgery in a hospital must be in writing unless the necessity for emergency treatment precludes obtaining written consent. $^{57}$

In some jurisdictions, hospitals may not have changed their procedures to reflect new laws. Unfortunately for children, many hospitals still require parental consent. ${ }^{I}$ Thus, physicians must familiarize themselves with the procedures of the hospitals where they have privileges, keeping in mind that the spirit of the legislation is to empower minors in their own treatment decisions.

\section{STEP 2: DisClosure OF RISKS}

The second step in the consent process is to advise the patient of all material risks of the procedure. Respect for self-determination and autonomy of a patient demands full disclosure of information, through "a process of negotiation, of education and collaboration." 2 (p. 202) This disclosure is measured by an objective standard of what a reasonable person in the patient's position would want to know. A patient may want to know much more than a physician considers is relevant to the patient. It is therefore essential to be completely open with the patient and to answer fully and frankly any questions that are asked. 
When it comes to reproductive health, the standard for disclosure is even higher. Courts place a high standard on these services because reproductive health is of such fundamental importance to personhood. When providing contraception, "alternative methods and the risks and reliability of each must be disclosed fully and frankly."24 (p. 66) Further, not only should the risks associated with contraception be discussed, but the risks associated with sexual activity and effective methods for reducing those risks should also be addressed. In the context of abortion, the physician must discuss the various techniques of abortion and the risks associated with each, as well as "the relative merits of having the abortion in a hospital or at a freestanding clinic." 24 (p. 66) In all cases, the physician should counsel regarding all aspects of sexual health.

\section{The INTERSECTION OF LAW, ETHICS, AND POLICY}

Although the mature minor rule has the advantage of permitting an individuated assessment without artificial constraints, it also carries the disadvantage of uncertainty..$^{24,42}$ Of course, no physician is ever legally obligated to provide contraceptives or other sexual health treatment to a mature minor; physicians who feel uncomfortable providing these services without parental consent are within their rights to withhold such services. Unfortunately, refusal to prescribe or treat, especially with a referral to another physician, has the major disadvantage of forcing the child to go elsewhere for care, or, since the child may reasonably assume that other physicians would hold the same views, to bypass treatment altogether. It is always important to consider the implications of refusing to provide treatment to a child who requests it, for in the end it may do more harm than good. When a physician is faced with an unfamiliar patient, and when the time limitations and circumstances make it difficult to have a lengthy conversation with the child, the best course of action may be to turn to ethical and policy considerations.

In the 3-part series Canadian Contraception Consensus, ${ }^{4}$ released this year, the Society of Obstetricians and Gynaecologists of Canada (SOGC) outlined some basic principles for the provision of contraceptive care. This consensus statement contains numerous useful guidelines, but of particular note is the strong recommendation that "[a]dolescents should have ready access to contraception and methods of STI prevention." "4. (p81) It is "essential" for adolescents to have access to a "supportive, encouraging, and non-judgmental environment, where confidentiality is assured." 4 (p. 381) Some of the most common reasons adolescents cite for not using contraception include fear of medical procedures, fear of resistance from health-care providers, and fear of lack of confidentiality. ${ }^{4}$ (p. 380$)$ The SOGC's policy of open access is, no doubt, in response to these concerns, and it recognizes the pragmatic necessity of maintaining a safe place to which adolescents can turn in times of need. In addition to this general policy, the Canadian Contraception Consensus suggests specific strategies for physicians in carrying out these services, and can be consulted as a useful resource.

\section{PHYSICIANS AND THE PARENTS OF THEIR ADOLESCENT PATIENT: THE DUTY OF CONFIDENTIALITY}

Although the adolescent patient has full rights to confidentiality, this does not mean that a physician ought to dismiss the inquiries of the parents. Recognition of the inherent value of family relationships is both ethical and legal, and it is important to be sensitive to a parent's concerns. At the same time, however, confidentiality must always be maintained. Therefore, it is essential to address a parent's concern through the adolescent, in hopes of achieving the best interests of the family as well as the best interests of the individual patient, as will be discussed below.

In McInerney v. MacDonald, ${ }^{58}$ the Supreme Court of Canada found that medical confidentiality may not be overridden unless there is a paramount reason for doing so. Therefore, physicians may face legal consequences for disclosing information given in professional confidence, but this area of the law remains unclear and underdeveloped. ${ }^{24}$ In McInerney, the court acknowledged the "fiduciary" relationship between physician and patient, in which the patient occupies a vulnerable position, relying upon and trusting in the physician's dutiful behaviour. This relationship imposes upon physicians certain fiduciary duties, including the duty to hold health information in confidence. A physician would be liable for even a "wellmeaning breach of confidence," such as involving parents without first obtaining the child's consent. ${ }^{2}$ (p. 214) While no actions for breach of professional confidence have been brought under this remedy, it has been argued that there is no reason why it would not apply in the future. ${ }^{24}$

Four provinces-British Columbia, Manitoba, Newfoundland, and Saskatchewan-have also passed a Privacy Act, ${ }^{59-62}$ in response to the common law's lack of protection for privacy interests. Each statute prohibits the willful violation of another person's privacy, but leaves it up to the courts to determine what amounts to an invasion of privacy. ${ }^{24}$ With respect to health information in particular, Ontario enacted the Personal Health Information Protection $\mathrm{Act}^{63}$ in May 2004, which requires express consent for disclosure of health information to

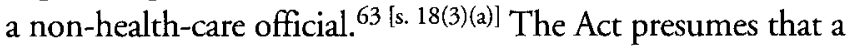
person is capable to consent to disclosure of information, ${ }^{63}[$ s.21(4)] and children under 16 do not need parental consent if they made a decision on their own about undergoing treatment or participating in counselling. ${ }^{63}[$ s. $23(1)(2)]$ Other provinces have similar legislation protecting health information ${ }^{64}$ or personal information ${ }^{65}$ in general.

Apart from common law and legislation, confidentiality is one of the cornerstones of an ethical medical practice. The duty of confidentiality is prescribed in the Canadian Medical Association (CMA) Code of Ethics, ${ }^{66}$ and a breach of this duty may 
give rise to professional sanctions. The CMA has also released a Health Information Privacy Code, ${ }^{67}$ which sets ethical standards above and beyond those provided in legislation. The Code describes privacy as a fundamental personal right and identifies the particularly sensitive nature of health information. Indeed, "the more sensitive the health information is likely to be ... the more important it is to ensure that consent [to disclosure] is voluntary and informed." ${ }^{\text {"6 (s. 5.12) }}$ Adolescent reproductive and sexual health is highly sensitive information and should, therefore, demand the highest fiduciary duty of confidence.

Most adolescents are tied to family members who seek to assert some control over their health care, presumably to aid in their well-being. How, then, should physicians respond to a parent who requests information about his or her child? The CMA, along with the Canadian Healthcare Association, the Canadian Nurses Association, and the Catholic Health Association of Canada, released a joint statement in 1998 on resolving such conflicts. ${ }^{68}$ The preamble recognizes the potential for disagreements about health care between any number of persons, but emphasizes that the needs, values, and preferences of the patient are to be the primary consideration when providing health care. While it is important to be sensitive to the needs and preferences of family members and significant others, a good "therapeutic relationship" is founded on mutual trust and respect berween providers and recipients of care. ${ }^{68 \text { [s. I(2-3)] }}$ Thus, physicians ought to encourage an adolescent to involve the parents in the discussion, however, providing information to parents without the child's consent would violate the necessary relationship of trust. Moreover, the right to confidentiality should not be limited to cases where the child is a mature minor. Unfortunately, there is debate on this point, ${ }^{3,42}$ but it has been argued, in the context of sexual health services, that any information that a child provides to a physician should always be held in confidence, regardless of whether the child has capacity to consent to treatment. Otherwise, minors would be unfairly required to disclose their personal information without knowing in advance whether such information would be held in confidence, given that an assessment of capacity can only be made after a full discussion. ${ }^{37}$ Although it may be difficult for parents to understand that they do not have a right to access their child's information, a physician ought to inform the parents of the physician's duty of confidentiality, and the fact that it applies equally in the case of children as it does in the case of adults.

\section{STIS: AN EXCEPTION TO THE RULE OF CONFIDENTIALITY}

While medical confidentiality is usually an inviolable right, there remain 2 important exceptions when dealing with sexual health services. Indeed, the CMA Code of Ethics recognizes that confidentiality is a qualified duty, subject to cases for which the law requires disclosure or when there is a risk of significant harm to others. ${ }^{66}$
The first exception to the rule of confidentiality is the reporting of child abuse, discussed above. A second exception is suspected or known cases of venereal disease. New Brunswick and Newfoundland and Labrador are unique in having legislation specific to venereal disease. All other provinces have general legislation covering all communicable disease, often accompanied by more specific regulations. Each province places statutory obligations both on potentially infected persons to seek and submit to treatment, and on their physicians to report information about the disease to a specified authority. Alberta, New Brunswick, Newfoundland and Labrador, and Ontario explicitly require parents to take responsibility for ensuring that their minor children (defined in most provinces as younger than age 16) comply with orders and directions. It is essential for physicians to familiarize themselves with this legislation, to ensure that they are meeting the reporting requirements while at the same time upholding confidentiality to the greatest possible degree. For example, the CMA notes that in such cases the patient's rights must be respected by taking all reasonable steps to inform the patient that confidentiality will be breached. ${ }^{66}$

When a physician diagnoses a health condition, such as AIDS, which may imperil a third party, does the physician have the liberty and/or the obligation to warn that third party? In some Canadian jurisdictions, including Nova Scotia and Saskatchewan, the obligation is placed on the infected person to notify their "at risk" contacts. In Manitoba, the physician is required to report contact information to the Minister of Health, who in turn may notify the contacts. In jurisdictions without specific guidelines for contact notification, there is a question about whether a physician should warn the prospective victim. If the patient's words or actions suggest a real danger that the infection may be passed on to others, the physician would probably not be liable for warning the third party, but authority on this point is scarce. As noted above, the CMA does recognize that confidentiality may be breached when there is a risk of significant harm to others. ${ }^{66}$ According to one scholar, "The best advice for the Canadian doctor is to avoid divulging information about the patient's venereal disease to those who might be infected, unless there is no other way to protect them." 26 (p. 21) Again, the law is less helpful than it could be. In 2000 , the CMA released a policy statement specific to the disclosure of HIV information. ${ }^{69}$ The policy statement encourages physicians to assist authorities in tracing and counselling all contacts of patients with HIV infection; recommends that the process be carried out with the cooperation and participation of the patient; and lists the conditions under which disclosure of an HIV-infected person's status to potential sexual partners may be justified, including when the patient has refused to inform the partner, and the partner has no other reasonable means of knowing. In all cases, the patient must be informed of the physician's intention to disclose the information to the partner. 


\section{CONCLUSIONS}

Physicians should feel comfortable providing reproductive and sexual health care to any adolescent, based on good medical and ethical understanding, and should accept the consent of an adolescent who understands the nature and consequences of the proposed treatment. Full informed consent should be obtained at all times, which will involve explaining risks and benefits and encouraging questions. The adolescent must be assured of the right to confidentiality (with certain exceptions, such as the duty to warn third parties and to report STIs to the appropriate authorities ${ }^{70}$; however, a physician may choose to communicate with the adolescent about the possibility of involving parents in major health decisions and to offer assistance in this regard.

\section{REFERENCES}

1. Schuman JP. When worlds collide: the legal rights of minors in Ontario to direct medical treatment. Appeal 1999;5:38-53.

2. Cote A.Telling the truth? Disclosure, therapeutic privilege and intersexuality in children. Health Law J 2000;8:199-216.

3. New South Wales Law Reform Commission. Minors' consent to medical treatment. Issues Paper 24 (2004). Available at <http://www.lawlink .nsw.gov.au//rc.nsf/pages/digest. 106>. Accessed June 3, 2004.

4. Black A, Francoeur D, Rowe T. Canadian contraception consensus. SOGC Clinical Practice Guidelines, No. 143, February-April 2004. J Obstet Gynaecol Can 2004;26(2): 143-56 (part I of 3);26(3):219-54 (part 2 of 3); 26(4):347-87 (part 3 of 3).

5. Criminal Code, R.S. 1985, c. C-46, s. 27I-3 (offences against the person and reputation).

6. Sansalone v.Wawanesa Mutual Insurance Co. (2000), (sub nom. Non-Marine Underwriters, Lloyd's of London v. Scalera) I85 D.L.R. (4th) I (S.C.C.).

7. R.v. S. (P.L.) (1990), 57 C.C.C. (3e) 53I (Nfld. C.A.), rev'd (199I), 64 C.C.C. (3d) 193 (S.C.C.).

8. R v.V. (K.B.) (1993), 82 C.C.C. (3d) 382 (S.C.C.).

9. R v.S. (V.C.A.), [2002] 5W.W.R. 385 (S.C.C.).

10. Criminal Code, R.S. 1985 , c. C-46, s. I5I (sexual interference).

II. Criminal Code, R.S. 1985, c. C-46, s. 152 (invitation to sexual touching).

12. R v.Sears (1990), 58 C.C.C. (3d) 62 (Man CA).

13. Criminal Code, R.S. 1985, c. C-46, s. I50.I (2) (consent no defenceexception).

14. Criminal Code, R.S. 1985 , c. C- 46, s. 153 (sexual exploitation). There is no need to prove that sexual activity resulted from an abuse of the position of authority or trust. See R v. Audet (1996), 48 C.R. (4th) I (S.C.C.); R v. Dussiaume (1995), 98 C.C.C. (3d) 217 (Ont. C.A.).

15. Rabinovitch J. Considerations on the age of consent to sexual activity: discussion paper from the Office of the Honourable Landon Pearson, Senator. March 2002. Available at <http://www.sen.parl.gc.ca/lpearson /Age\%20of\%20Consent.pdP. Accessed May 5, 2004.

16. Pilon M. Law and Government Division of Parliament of Canada. Canada's legal age of consent to sexual activity. Jan 25, 1999, revised April 12, 200 I. Available at <http://www.parl.gc.ca/information/library /PRBpubs/prb993-e.htm>. Accessed May 5, 2004.
17. Wilson S. Good girls do: school counsellors, researchers and teenagers themselves say that girls as young as 12 and 13 are performing oral sex. The Globe and Mail 2004 Feb 7;F4.

18. R. v. Chase, [1987] 2 S.C.R. 293, 45 D.L.R. (4th) 98.

19. R. v. M. (C.) (1995), 23 O.R. (3d) 629.

20. R. v. Roy (1998), 101 D.L.R. (4th) 148

2I. R v. Roth (2002), 306 A.R. 387 (Q.B.).

22. Gillick v. West Norfolk and Wisbech Area Health Authority, [1985] 3 All E.R. 402 (H.L.).

23. Cook R, Dickens B, Fathalla M. Reproductive health and human rights: integrating medicine, ethics, and law. Oxford: Clarendon Press; 2003.

24. Sneiderman B, Irvine J, Osborne P, editors. Canadian medical law: an introduction for physicians, nurses and other health care professionals. 3rd ed. Scarborough:Thomson Carswell; 2003.

25. Renke W.The confidentiality of health information in the criminal law. Health Law R 1998;6(3):3-11.

26. Picard El, Robertson GB. Legal liability of doctors and hospitals in Canada. 3rd ed. Toronto: Carswell; 1996.

27. Report of the Commission of Inquiry into the Confidentiality of Health Information, volume 2. Ontario: Queen's Printer; 1980.

28. Child and Family Services Act, R.S.O. 1990, c. C.I I, as amended.

29. Child, Family and Community Service Act, R.S.B.C. 1996, c. 46.

30. Child Welfare Act, R.S.A. 2000 , c. C. 12.

31. Child and Family Services Act, S.S. 1989-90, c. C-7.2

32. Child and Family Services Act, C.C.S.M., c. C80.

33. Children and Family Services Act, S.N.S. 1990, c. 5.

34. Family Services Act, S.N.B. 1980, c. F-2.2.

35. Child abuse: a fact sheet from the Department of Justice Canada. Available at <http://canada.justice.gc.ca./en/ps/fm/childafs.html>. Accessed May 5, 2004.

36. Ministry of Children and Family Development.The B.C. handbook for action on child abuse and neglect.Victoria: Queen's Printer for British Columbia; 2003. Available at <http://www.mcf.gov.bc.ca/child _protection/pdf/handbook_action_child_abuse.pdf $>$. Accessed October 13,2004.

37. Fortin J. Children's rights and the developing law. London: Butterworths; 1998.

38. Reddy DM, Fleming R, Swain C. Effect of mandatory parental notification on adolescent girls' use of health care services. JAMA 2002;288(6):710-4.

39. Aid for Women v. Foulston, 327 F. Supp 2d I273, 2004 U.S. Dist. LEXIS 14238.

40. Reibl v. Hughes (I980), 1 I4 D.L.R. (3d) I, 2 S.C.R. 880.

41. Rozovsky L.The Canadian law of consent to treatment. 2nd ed. Toronto: Butterworths; 1997.

42. Gilmour JM. Children, adolescents and health care. In: Downie J, Caulfield T, Flood $C$, editors. Canadian health law and policy. 2nd ed. Toronto: Butterworths; 2002. p. $204-49$.

43. Region 2 Hospital Corp. v.Walker (1994), 150 N.B.R. (2d) 362, 116 D.L.R. (4th) 477.

44. Health Care Consent Act, 1996, S.O. 1996, c. 2, Schedule A.

45. Health Care Consent Act, 1996, S.O. 1996, c. 2, s. 4(I).

46. Infants Act, R.S.B.C. 1996, c. 223, s. 17(3). 
47. Medical Consent of Minors Act, S.N.B. 1976, c. M-6. I, s. 3(I).

48. Health Care Directives Act, C.C.S.M., c. H27, s. 4(2)

49. Van Mol (Guardian ad litem of) v. Ashmore (1999), 58 B.C.L.R. (3d) 305 (C.A.).

50. Manitoba Law Reform Commission. Minor's consent to health care: report 91. 1995.

51. Hoffman B.The law of consent to treatment in Ontario. 2nd ed. Toronto: Butterworths; 1997.

52. C. (G.C.) v. New Brunswick (Minister of Health \& Community Services), [1988] I S.C.R. 1073.

53. Ney v. Canada (Attorney General), (1993), 79 B.C.L.R. (2d) 47, I 993 CarswellBC I 13 (S.C.).

54. ReY.(A.) (1993), III Nfld. \& P.E.I.R. 91 (Nfld. S.C.)

55. McKay-Panos L. Seniors, youth, \& consent to treatment. Law Now 2000; Oct/Nov:18-9.

56. C. (J.S.) v.Wren (1986), [1987] 2W.W.R. 669, 35 D.L.R. (4th) 419 (Alta. C.A.).

57. See e.g. Hospital Management Regulations, EC 574/76 [now amended, EC357/00], s.48 made pursuant to Hospitals Act, R.S.P.E.I. 1988, c.H-10.

58. Mclnerney v. MacDonald, [1992] 2 S.C.R. 138.

59. Privacy Act, R.S.B.C. 1996, c. 373.

60. Privacy Act, C.C.S.M. c. P125.
61. Privacy Act, R.S.N.L. 1990, c. P-22.

62. Privacy Act, R.S.S. 1978, c. P-24

63. Personal Health Information Protection Act, 2004, S.0. 2004, c. 3. Available at <http://www.e-laws.gov.on.ca/DBLaws/Source/Statutes/English 12004/S04003_e.htm>. Accessed May 31, 2004.

64. See e.g. Health Information Act, R.S.A. 2000, c. H-5.

65. See e.g. Personal Information Protection Act, S.B.C. 2003, c. 63.

66. Canadian Medical Association Code of Ethics. s. 22. Available at <http://www.cma.ca/index.cfm/ci_id/24/9/la_id//.htm>. Accessed May 31, 2004.

67. Canadian Medical Association Health Information Privacy Code. 1998. Available at <http://www.cma.ca/index.cfm/ci_id/3216/la_id/l.htm>. Accessed May 31, 2004.

68. Canadian Medical Association. Joint statement on preventing and resolving ethical conflicts involving health care providers and persons receiving care. $1998 \mathrm{Dec} 4-5$. Available at <http://www.cma.ca/index $. c f m / c i \_i d / 3217 / l a \_i d / / . h t m>$. Accessed May 31, 2004.

69. Canadian Medical Association Policy Statement: Acquired immunodeficiency syndrome. 2000. Available at <http://www.cma.ca/multimedia /staticContent/HTML/NO//2/where_we_stand/acquired_imunodeficien cy_syndrome.pdf>. Accessed May 31, 2004.

70. Flagler E. Royal College of Physicians and Surgeons of Canada. Obstetrics and gynaecology curriculum. Available at <http://rcpsc.medical.org /ethics/obgyn/index.php>. Accessed May 5, 2004.

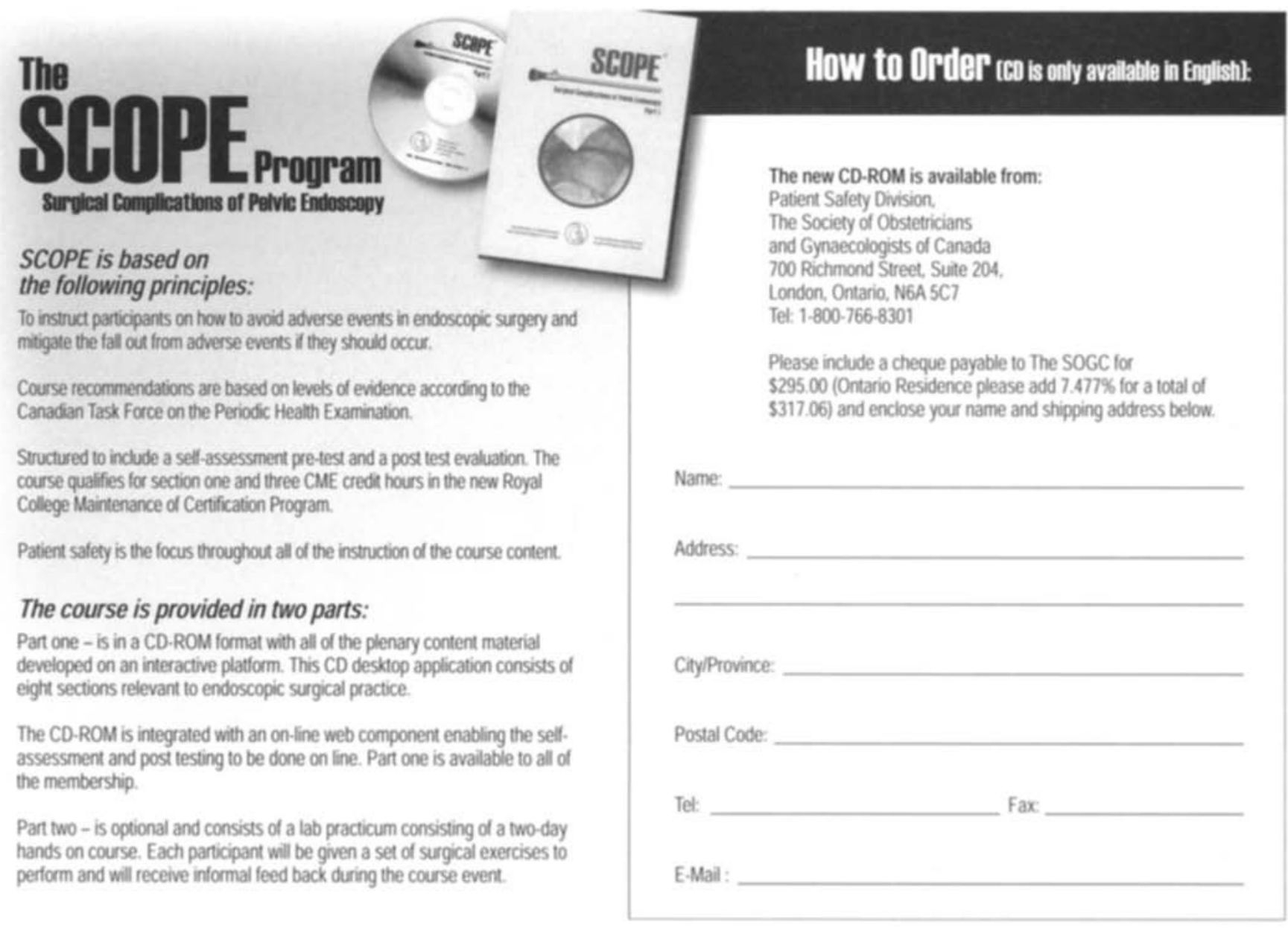

